J Am Chem Soc. 2017 March 15; 139(10): 3911-3916. doi:10.1021/jacs.7b00943.

\title{
Synthesis of Complex Tertiary Glycolates by Enantioconvergent Arylation of Stereochemically Labile a-Keto Esters
}

\author{
Samuel L. Bartlett, Kimberly M. Keiter, and Jeffrey S. Johnson ${ }^{*}$ \\ Department of Chemistry, University of North Carolina at Chapel Hill, Chapel Hill, North Carolina \\ 27599-3290 United States
}

\begin{abstract}
Enantioconvergent arylation reactions of boronic acids and racemic $\beta$-stereogenic $\alpha$-keto esters have been developed. The reactions are catalyzed by a chiral (diene) $\mathrm{Rh}(\mathrm{I})$ complex and provide a wide array of $\beta$-stereogenic tertiary aryl glycolate derivatives with high levels of diastereo- and enantioselectivity. Racemization studies employing a series of sterically differentiated tertiary amines suggest that the steric nature of the amine base additive exerts a significant influence on the rate of substrate racemization.
\end{abstract}

\section{Graphical Abstract}

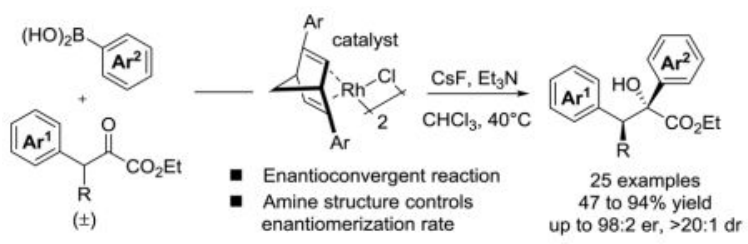

\section{Introduction}

The conversion of racemic a-stereogenic ketones to enantiomerically enriched alcohol building blocks through transformation of the carbonyl functionality is an enabling chemical transformation. ${ }^{1}$ Transition metal-catalyzed dynamic kinetic hydrogenation reactions, pioneered by Noyori, have been widely employed for the production of enantioenriched secondary alcohols. ${ }^{2}$ The synthesis of tertiary alcohols through the enantioconvergent addition of stabilized carbon nucleophiles to configurationally labile electrophiles is comparatively less common. ${ }^{3}$ Reported examples employ basic catalysts or additives to promote simultaneous activation of the pro-nucleophile and enantiomerization of the electrophile. Considering this dual role of base in the context of designing other stereoconvergent processes, the transition metal-catalyzed addition of nonstabilized carbon

Corresponding Author: jsj@unc.edu.

Notes

The authors declare no competing financial interests.

Supporting Information

Experimental procedures, spectral and analytical data, and CIF files for crystallographic data. This material is available free of charge via the Internet at http://pubs.acs.org. 
nucleophiles to ketones emerged as a compelling opportunity to generate complex tertiary alcohols not accessible through other methods (Scheme 1, B). The Hayashi-Miyaura type reactions typically rely on the base promoted transmetallation of an organoboron or organosilicon pro-nucleophile to a chiral metal complex. ${ }^{4}$ As an example, the enantioselective addition of arylboronic acids to carbonyl derivatives, including a-keto esters, has been widely developed (Scheme $1, \mathrm{C}$ ) ${ }^{5}$ Considering their chemical stability, ease of handling and broad commercial availability, ${ }^{6}$ we envisioned the deployment of arylboronic acids in an enantioconvergent addition to racemic a-keto ester electrophiles electrophiles would facilitate the production of diverse, stereochemically complex glycolate architectures. The purpose of this article is to convey experimental findings related to the dynamic kinetic 1,2-addition of arylboronic acids to racemic a-keto esters (Scheme 1, D).

Carbonyl electrophiles and their derivatives lacking electron withdrawing functionality (i.e. ketone, ester, or halogen) at the chiral a center are underutilized in dynamic kinetic resolutions (DKR). List and Zhao have reported a dynamic kinetic reductive aminations employing a-alkyl, aryl branched imines that presumably racemize via enamine intermediates. ${ }^{7}$ The cyclohexanecarboxaldehyde derivatives utilized by Ward and coworkers likely racemize via an analogous pathway. ${ }^{3 e}$ Dynamic kinetic hydrogenations of nonactivated aldehydes and ketones have been shown to occur in the presence of tertbutoxide bases. ${ }^{8}$ Nevertheless, considering that facile racemization is essential, the execution of DKRs employing compounds of lower acidity is more challenging. ${ }^{9}$ However, in this context the use of less activated substrates would allow access to heretofore unknown glycolate architectures.

\section{Results and Discussion}

In light of the considerations described above, the $\beta$-alkyl, aryl substituted $a$-keto ester derivative 1a was chosen as a model substrate for this transformation (Table 1). Our group has previously developed dynamic kinetic resolutions of a-keto esters that occur in the presence of tertiary amines; ${ }^{21-n, 3 a}$ therefore, we reasoned that an amine base would promote substrate racemization. Sterically hindered Hünig's base $\left({ }^{i} \mathrm{Pr}_{2} \mathrm{NEt}\right)$ was initially selected in an effort to minimize interference with the Rh(I)-catalyst through nonproductive binding. A substoichiometric quantity of potassium hydroxide was employed because analogous conditions promote the Hayashi-Miyaura arylation of isatins and 1a is sensitive to stoichiometric hydroxide base. ${ }^{10}$ An initial evaluation of ligands revealed that the $\mathrm{Ph}$ substituted norbornadiene derived ligand $\mathbf{A}$ developed by Hayashi and co-workers ${ }^{11}$ provided promising levels of enantioselectivity, although low conversion was observed under these conditions (entry 1). Further screening showed the $4-\mathrm{CF}_{3} \mathrm{C}_{6} \mathrm{H}_{4}$-and 3,5- $\left(\mathrm{CF}_{3}\right)_{2} \mathrm{C}_{6} \mathrm{H}_{3}-$ substituted analogues $\mathbf{B}$ and $\mathbf{C}$ provided higher levels of enantioselection; however, conversion remained low (entries 2 and 3 ). The supposed low acidity of these substrates caused us to wonder if a simple kinetic resolution was occurring under these conditions, but this possibility was ruled out by isolation of racemic unreacted 1a from entry 3 . Interestingly, the benzyl substituted ligand $\mathbf{D}$ provided low enantioselectivity slightly in favor of opposite enantiomer, while also exhibiting drastically lower levels of diastereocontrol over the formation of $\mathbf{3 a}$ (entry 4). Switching the inorganic base promoter from potassium hydroxide to $\mathrm{CsF}$ while increasing the loading to 3.0 equiv allowed for full 
conversion to the desired aryl glycolate, albeit with a striking drop in enantioselectivity (entry 5). Simply replacing Hünig's base with triethylamine restored the previously observed levels of enantioselectivity (entry 6). Further increasing the amount of triethylamine to 6.0 equiv provided higher levels of enantioselectivity (entry 7), although a longer reaction time was necessary to achieve full conversion under these conditions. Satisfactory levels of enantioselectivity were achieved when chloroform was used as solvent in place of methylene chloride (entry 8). At this stage of optimization it was noted that both the $4-\mathrm{CF}_{3} \mathrm{C}_{6} \mathrm{H}_{4}$ - and 3,5- $\left(\mathrm{CF}_{3}\right)_{2} \mathrm{C}_{6} \mathrm{H}_{3}$-substituted norbornadiene ligands $\mathbf{B}$ and $\mathbf{C}$ provided identical levels of enantioselectivity (entries 8 and 9). Running the reaction at $60{ }^{\circ} \mathrm{C}$ does not influence the enantio- or diastereoselectivity of the process (entry 10). Substituting the ethyl ester of $\mathbf{1 a}$ with bulkier ${ }^{t} \mathrm{Bu}$ or $\mathrm{Bn}$ groups (entries 11 and 12 , respectively) did not result in improved enantioselectivity. Finally, although phosphine ${ }^{5 b}$ and phosphite ${ }^{5 a}$ ligands have been utilized in Hayashi-Miyaura-type arylation reactions of a-keto esters, a complex of triphenylphosphite (E, entry 13) as well as hydroxy[( $S$ )-BINAP]rhodium(I) dimer (F, entry 14) failed to catalyze this transformation.

At this juncture we sought to understand the large contribution to product enantioselectivity associated with the superficially similar structure of the amine base additive. We hypothesize that this difference might arise from a faster rate of starting material racemization under the action of triethylamine. Using Hünig's base in conjunction with low inorganic base concentration resulted in high levels of product enantioselectivity and the unreacted starting material recovered from the reaction was not enantioenriched (entry 3, Table 1), suggesting that an efficient dynamic kinetic resolution is occurring under these conditions. We postulate that under conditions of low inorganic base concentration the arylation reaction is slow relative to Hünig's base promoted racemization $\left(k_{\text {rac }}>k_{\text {fast }}\right)^{9}$ resulting in a dynamic kinetic resolution. However, in entry 5 the higher loading of $\mathrm{CsF}$ results in a faster arylation reaction for both substrate enantiomers, presumably due to higher rates of transmetallation, while the rate of racemization by Hünig's base occurs too slowly for efficient dynamic kinetic resolution. ${ }^{12}$ To gain further insight into this phenomenon and to provide support for our hypothesis we studied the rate of racemization of 1a using an array of tertiary amine bases (Figure 1). At room temperature racemization with triethylamine was rapid; within eight minutes the extent of racemization had reached $87 \%$ and complete racemization occurred after $20 \mathrm{~min}$. Tri- $n$-butylamine exhibited a noticeably slower racemization profile, but was still nearly complete within $20 \mathrm{~min}$. In contrast to triethylamine and tri- $n$-butylamine, the alkyl branched Hünig's base displayed a slow racemization profile, and 1a was still measurably enriched after approximately $1.7 \mathrm{~h}$ at room temperature. When studied at $40{ }^{\circ} \mathrm{C}$ in the presence of 6 equiv of Hünig's base, racemization of 1a was enhanced but complete racemization only occurred after $1 \mathrm{~h}$. Thus, although Hünig's base exhibits greater thermodynamic basicity than triethylamine it is less effective at promoting the racemization of 1a. ${ }^{13}$ Finally, $N$-methylpyrroldine, which possesses lower thermodynamic basicity than triethylamine, ${ }^{14}$ displayed the fastest racemization profile, promoting complete racemization of 1a in under two minutes. The observed trend suggests the kinetic basicity of the tertiary amine exerts a larger influence on the racemization of 1a than its thermodynamic basicity. This observation may prove to be generally important in the de novo design novel dynamic kinetic resolutions involving enolizable carbonyl substrates. 
With optimal reaction conditions in hand we began to study the scope of the process with respect to the arylboronic acid component (Table 2). It should be noted that while catalysts $\mathbf{B}$ and $\mathbf{C}$ provide identical levels of selectivity for product $\mathbf{3 a}$, in certain cases it was found that one catalyst was more selective for a particular substrate. Ultimately, electron-rich arylboronic acids were found to be suitable reaction partners as the $p$-tolyl adduct $\mathbf{3 b}$ was formed in high yield with high levels of diastereo- and enantiocontrol. Electron-poor arylboronic acids could also be used; however, in the case of $p$-fluoro- and $p$ chlorophenylboronic acid a larger excess was required to achieve good yields. Nevertheless, high levels of diastereo- and enantioselectivity were still observed for addition products 3c and 3d. Substitution of the arylboronic acid at the $m$-position was also tolerated. For instance, the $m$-methoxy and $m$-tolyl adducts $\mathbf{3 e}$ and $\mathbf{3 f}$ were obtained in good yield, with high levels of stereocontrol. Electron-withdrawing substituents were also tolerated at this position and the use of $m$-chlorophenylboronic acid afforded the desired arylation product $3 \mathbf{g}$ in good yield with high levels of stereocontrol. Polyaromatic boronic acids were also suitable substrates for this transformation, as the 2-naphthyl adduct $\mathbf{3 h}$ could be obtained in good yield with similarly high levels of diastereo- and enantiocontrol. The sterically demanding $O$-methoxy adduct $\mathbf{3 i}$ was formed in good yield with high levels of enantiocontrol, although in this instance a relatively large excess of the boronic acid substrate was required to achieve full conversion. Finally, we found that even unprotected 6indoylboronic acid could be employed, furnishing adduct $\mathbf{3 j}$, while maintaining reaction efficiency. It should be noted that at this stage of optimization certain electron poor arylboronic acid substrates cannot be used, as the 4-pyridyl and 5-indazole adducts $\mathbf{3 k}$ and $\mathbf{3 l}$ were not formed. In addition, the reaction with 2-thienylboronic acid only reached $11 \%$ conversion after $36 \mathrm{~h}$ under the optimized reaction conditions (not shown). Efforts to address these limitations are currently underway in our laboratory.

Next, we explored the scope of the reaction with respect to the a-keto ester reaction partner (Table 2). Substrates bearing electron donating substituents at the para-position of the aryl ring were suitable reaction partners. For example, the $p$-tolyl substituted product $\mathbf{3 m}$ was obtained in good yield with high levels of stereocontrol. Higher levels of enantioselectivity were observed with this substrate when 2-naphthylboronic acid was employed as a nucleophile furnishing the addition product 3n. Apparently, the electron-rich $p$-methoxy substituted substrate was subject to facile racemization under the reaction conditions, as product 30 could also be obtained in good yield with high levels of stereocontrol. An ortho-F substituted $\mathbf{a}$-keto ester was subject to phenylboronic acid addition, producing $\mathbf{3 p}$ in acceptable yield and high diastereoselectivity and decent levels of enantiocontrol. The $o$ tolyl product 3q was afforded in 57\% yield, and 94:6 er, while the $m$-tolyl product $3 \mathbf{r}$ was formed in $88 \%$ yield with $96: 4$ er, suggesting that the steric nature of the a-keto ester aryl component has a slight impact on reaction efficiency and enantioselectivity. A 2-naphthyl substituted a-keto ester could also be used, affording addition product $3 \mathbf{s}$ with high levels of enantio- and diastereoselectivity. Product 3s could be enriched to 97.5:2.5 er following a single crystallization. Notably, arylation of an unprotected 3-indole substituted a-keto ester with 6-indoleboronic acid afforded bis(indole) adduct $3 \mathrm{t}$ in good yield with high levels of selectivity. The use of 2-naphthyl and $m$-tolylboronic acid was also successful with this aketo ester (see supporting information). Larger alkyl substituents at the $\beta$-position were 
tolerated and the $\beta$-ethyl substituted product $3 \mathbf{u}$ was obtained in good yield with acceptable levels of enantiocontrol. Product $3 \mathbf{u}$ could be obtained as a single enantiomer in acceptable yield following a single recrystallization. The arylation reaction exhibited functional group chemoselectivity in the presence of competing functionality as the bromoaryl and $\beta$-allyl substituted product $\mathbf{3 v}$ was obtained in acceptable yield with high levels of stereocontrol. Notably, less than $10 \%$ of Heck-type co-products ${ }^{15}$ were observed during formation of $\mathbf{3 v}$. Additionally, no Suzuki-type products are observed in this process. The branched diester product was formed in excellent yield. Although lower levels of enantiocontrol were observed in this reaction, product $\mathbf{3 w}$ can be accessed as a single enantiomer in acceptable yield following a single crystallization. Finally, although pyridine containing boronic acids are not successful reaction partners at this stage of optimization, a 3-pyridyl substituted aketo ester was tolerated under the reaction conditions and afforded arylation product $\mathbf{3 x}$ in good yields with high diastereo- and enantiocontrol. Product $\mathbf{3 x}$ could also be recovered as a single enantiomer, albeit in lower yield, after a single crystallization. Substrates bearing only aliphactic substitution at the $\beta$-position have note been tested at this juncture; presumably these substrates are less acidic and would be challenging to implement under the present reaction conditions.

Having learned the scope of the DKR arylation process, we sought to examine the effect of increasing the scale of the reaction while simultaneously decreasing the catalyst loading (Scheme 2). The 4-bromo substituted a-keto ester 1y underwent arylation with 2naphthylboronic acid on $1 \mathrm{mmol}$ scale using $0.5 \mathrm{~mol} \%$ of the catalyst ( $1 \mathrm{~mol} \% \mathrm{Rh}$ ) to afford $\mathbf{3 y}$ in good yield with high levels of diastereo- and enantiocontrol. Product $\mathbf{3 y}$ could be recrystallized to 99:1 er allowing the absolute stereochemistry of $\mathbf{3 y}$ to be determined via $\mathrm{X}$-ray crystallography. The configuration of the other arylation products $\mathbf{3 a}-\mathbf{3 x}$ were assigned by analogy. ${ }^{16}$ The observed stereochemistry can be attributed to the $\mathrm{C} 2$-symmetric nature of $(R, R)$-catalyst $\mathbf{C}$ which enforces high levels of enantiocontrol in this reaction by effectively blocking the shaded quadrants in the stereochemical model shown in Scheme 2; the bulky $s p^{3}$ center is guided to the top left quadrant. The diastereoselectivity of this transformation is in accord with the Felkin-Ahn model. ${ }^{17}$

Aromatic interactions appear to be important for achieving high levels of enantio- and diastereoselectivity as evidenced by the inferior results using the benzyl substituted catalyst D.

Finally, considering the sterically encumbered nature of the tertiary alcohol installed in the arylation reaction we wondered if this functionality could be leveraged in downstream transformations. Preliminary findings have been promising. For instance, unsaturated alcohol $3 \mathrm{v}$ undergoes iodoetherification to tetrahydrofuran $4 \mathrm{v}$ in $66 \%$ yield albeit without diastereoselectivity. The diastereomers of $\mathbf{4} \mathbf{v}$ were easily separated by silica gel column chromatography.

\section{Conclusion}

In summary, we have developed an enantioconvergent arylation of racemic $\beta$-alkyl substituted a-keto esters catalyzed by a chiral rhodium-diene complex. A wide range of 
complex aryl glycolate derivatives could be obtained in good yields with high levels of stereocontrol. Notably, despite the longstanding use of transition metal catalysts in dynamic kinetic hydrogenations, this is the first use of analogous catalysts for the installation of C-C bonds in a dynamic kinetic addition to carbonyl electrophiles. Considering the substantial number of commercially available arylboronic acid derivatives and the well-recognized biological activity of the glycolic acid substructure, ${ }^{18}$ this chemistry opens the door to a diverse array of interesting building blocks. Although racemization rate is central to efficient dynamic kinetic resolutions ${ }^{9}$ it is rarely discussed or studied in detail, here we have shown that the racemization of less acidic $\beta$-alkyl/aryl substituted $\alpha$-keto esters is strongly linked to the steric size of a tertiary amine additive. Preliminary results show that the products of this reaction can be utilized in additional downstream transformations including the synthesis of valuable tetrahydrofuran derivatives. Extension of this work to other classes of nonstabilized carbon centered nucleophiles is currently underway in our laboratory and will be reported in due course.

\section{Supplementary Material}

Refer to Web version on PubMed Central for supplementary material.

\section{Acknowledgments}

The project described was supported by Awards R01 GM103855 and R35 GM118055 from the National Institute of General Medical Sciences. K. M. K. gratefully acknowledges support from the Matthew Neely Jackson Undergraduate Research Fellowship. X-ray crystallography was performed by Dr. Peter White.

\section{References}

1. Reviews on dynamic kinetic resolution: Caddick S, Jenkins K. Chem Soc Rev. 1996; 25:447456.Huerta FF, Minidis ABE, Bäckvall JE. Chem Soc Rev. 2001; 30:321-331.Pellissier H. Tetrahedron. 2003; 59:8291-8327.Pellissier H. Tetrahedron. 2011; 67:3769-3802.

2. For select literature examples, see: Kitamura M, Tokunaga M, Noyori R. J Am Chem Soc. 1993; 115:144-152.Noyori R, Tokunaga M, Kitamura M. Bull Chem Soc Jpn. 1995; 68:36.Eustache F, Dalko PI, Cossy J. Org Lett. 2002; 4:1263-1265. [PubMed: 11950338] Ros A, Magriz A, Dietrich H, Lassaletta JM, Fernández R. Tetrahedron. 2007; 63:7532-7537.Ros A, Magriz A, Dietrich H, Ford M, Fernández R, Lassaletta JM. Adv Synth Catal. 2005; 347:1917-1920.Ding Z, Yang J, Wang T, Shen Z, Zhang Y. Chem Commun. 2009:571-573.Huang X-F, Zhang S-Y, Geng Z-C, Kwok C-Y, Liu P, Li H-Y, Wang XW. Adv Synth Catal. 2013; 355:2860-2872.Cheng T, Ye Q, Zhao Q, Liu G. Org Lett. 2015; 17:4972-4975. [PubMed: 26439249] Son SM, Lee H-K. J Org Chem. 2014; 79:2666-2681. [PubMed: 24568588] Cartigny D, Püntener K, Ayad T, Scalone M, Ratovelomanana-Vidal V. Org Lett. 2010; 12:3788-3791. [PubMed: 20672834] Steward KM, Gentry EC, Johnson JS. J Am Chem Soc. 2012; 134:7329-7332. [PubMed: 22509806] Steward KM, Corbett MT, Goodman CG, Johnson JS. J Am Chem Soc. 2012; 134:20197-20206. [PubMed: 23186551] Corbett MT, Johnson JS. J Am Chem Soc. 2013; 135:594-597. [PubMed: 23297694] Goodman CG, Do DT, Johnson JS. Org Lett. 2013; 15:2446-2449. [PubMed: 23631467] Bao D-H, Gu S-H, Xie J-H, Zhou Q-L. Org Lett. 2016; 19:118-121. [PubMed: 27936808]

3. Known examples: Corbett MT, Johnson JS. Angew Chem Int Ed. 2014; 53:255-259.Goodman CG, Johnson JS. J Am Chem Soc. 2014; 136:14698-14701. [PubMed: 25299730] Goodman CG, Walker MM, Johnson JS. J Am Chem Soc. 2015; 137:122-125. [PubMed: 25533016] Cohen DT, Eichman CC, Phillips EM, Zarefsky ER, Scheidt KA. Angew Chem Int Ed. 2012; 51:7309-7313.Ward DE, Jheengut V, Akinnusi OT. Org Lett. 2005; 7:1181-1184. [PubMed: 15760169] Bergeron-Brelk M, Teoh T, Britton R. Org Lett. 2013; 15:3554-3557. [PubMed: 23819733] Tang J, Wang T, Ding Z, Shen Z, Zhang Y. Org Biomol Chem. 2009; 7:2208-2213. [PubMed: 19421462] Calter MA, Phillips 
RM, Flaschenriem C. J Am Chem Soc. 2005; 127:14566-14567. [PubMed: 16231897] Calter M, Li N. Org Lett. 2011; 13:3686-3689. [PubMed: 21667928]

4. a) Sakai M, Ueda M, Miyaura N. Angew Chem, Int, Ed. 1998; 37:3279-3281.b) Takaya Y, Ogasawara M, Hayashi T. J Am Chem Soc. 1998; 120:5579-5580.c) Tian P, Dong H-Q, Lin G-Q. ACS Catal. 2012; 2:95-119.

5. a) Duan H-F, Xie J-H, Qiao X-C, Wang L-X, Zhou Q-L. Angew Chem Int Ed. 2008; 47:43514353.b) Cai F, Pu X, Qi X, Lynch V, Radha A, Ready JM. J Am Chem Soc. 2011; 133:1806618069. 126,8910. [PubMed: 21972824] c) Yamamoto Y, Shirai T, Watanabe M, Kurihara K, Miyaura N. Molecules. 2011; 16:5020-5034. [PubMed: 21694668] d) Zhu T-S, Jin S-S, Xu M-H. Angew Chem Int Ed. 2012; 51:780-783.e) Zhu T-S, Xu M-H. Chin J Chem. 2013; 31:321-328.

6. Greater than 1000 boronic acids are available from Sigma-Aldrich.

7. a) Hoffman S, Nicoletti M, List B. J Am Chem Soc. 2006; 128:13074-13075. [PubMed: 17017786] b) Rong Z-Q, Zhang Y, Chua RHB, Pan H-J, Zhao Y. J Am Chem Soc. 2015; 137:4944-4947. [PubMed: 25837014]

8. Xie J-H, Zhou Q-L. Aldrichimica Acta. 2015; 48:33-39.

9. Walsh, PJ., Kozlowski, MC. Fundamentals of Asymmetric Catalysis. University Science Books; California: 2009. p. 272

10. Shintani R, Inoue M, Hayashi T. Angew Chem, Int Ed. 2006; 45:3353-3356.

11. a) Hayashi T, Ueyama K, Tokunaga N, Yoshida K. J Am Chem Soc. 2003; 125:11508-11509. [PubMed: 13129348] b) Berthon-Gelloz G, Hayashi T. J Org Chem. 2006; 71:8957-8960. [PubMed: 17081029]

12. Rovis and co-workers noted a similar effect during the development of an asymmetric glyoxamidation of alkylidene malonates: Liu Q, Perreault S, Rovis T. J Am Chem Soc. 2008; 130:14066-14067. [PubMed: 18834123]

13. Scherrer RA, Donovan RA. Anal Chem. 2009; 81:2768-2778. [PubMed: 19265385]

14. Stoimenovski J, Izgorodina E-I, MacFarlane D-R. Phys Chem Chem Phys. 2010; 12:10341-10347. [PubMed: 20601995]

15. When preparing the racemic standards for $\beta$-allyl substituted products such as $3 \mathrm{v}$ significant amounts of the Heck product shown below was observed:

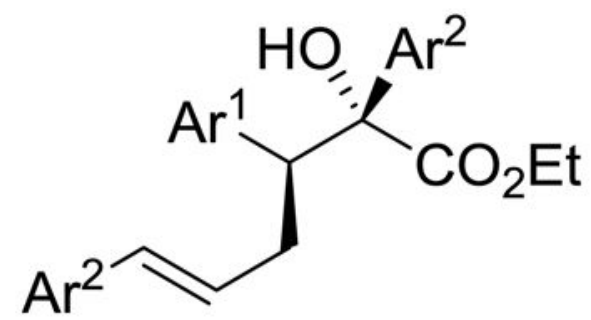

16. CCDC 1502349 , CCDC 1502350 , and CCDC 1529845 contain the supplementary crystallographic data for this paper. This data can be obtained free of charge from the Cambridge Crystallographic Date Centre via www.ccdc.cam.ac.uk/data_request/cif.

17. a) Cherest M, Felkin H, Prudent N. Tetrahedron Lett. 1968; 18:2199-2204.b) Anh NT, Eisenstein O. Tetrahedron Lett. 1976:155-158.

18. Kiefel MJ, Itzstein MV. Chem Rev. 2002; 102:471-490. [PubMed: 11841251] 
<smiles>CCOC(=O)C(=O)C(C)c1ccc(Cl)cc1</smiles>

M

$1 \mathrm{a}$

$76 \%$ ee

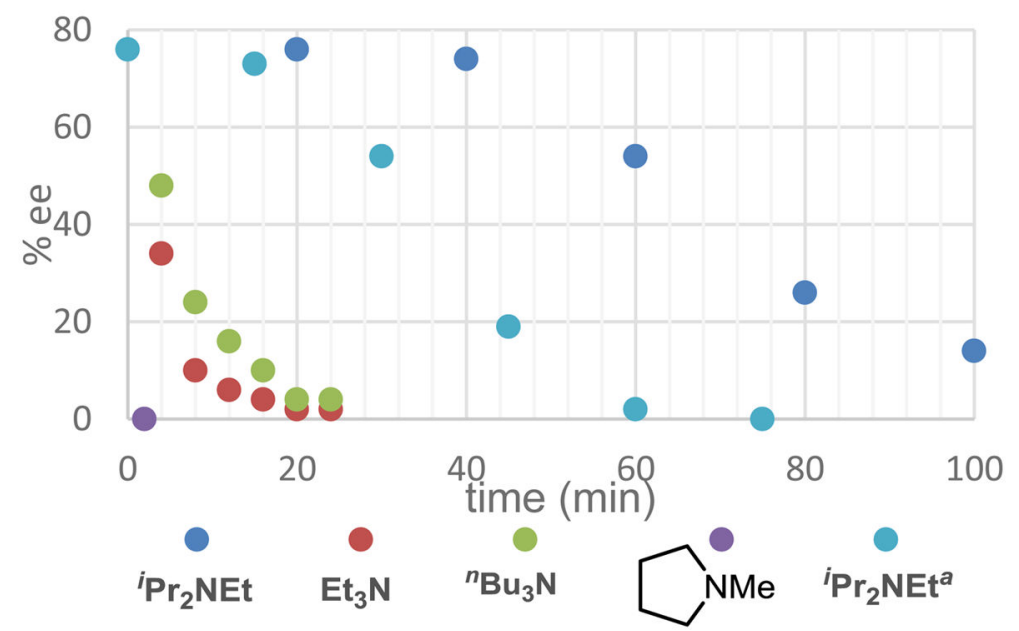

Figure 1. Influence of Base Structure on Racemization Rate a) Trial conducted at $40^{\circ} \mathrm{C}$. 6.0 equiv Hünig's base. 
A. Noyori Dynamic Kinetic Hydrogenation: 1989

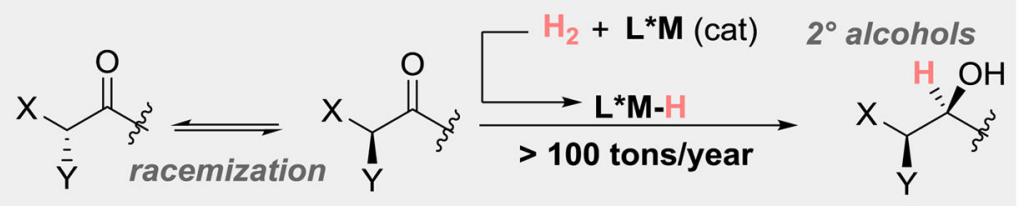

B. Enantioconvergent Nonstabilized Nucleophile Additions

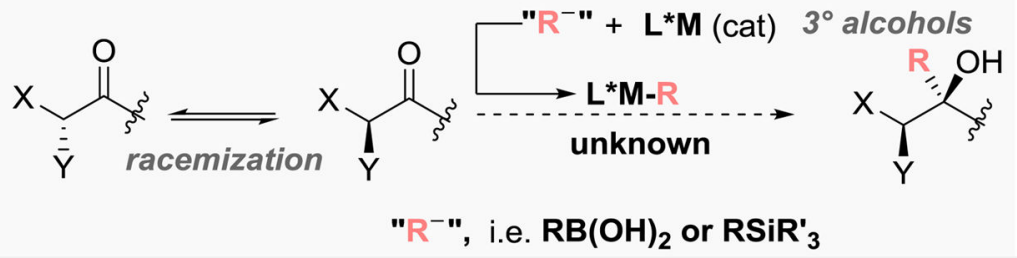

C. Hayashi-Miyaura-Type Arylation of $\alpha-K e t o$ Esters

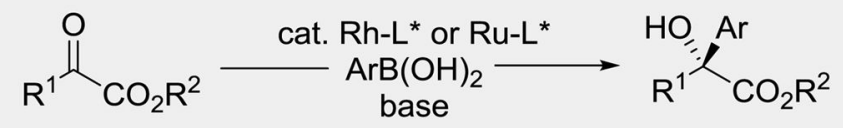

$\mathrm{L}^{*}=$ phosphite (Zhou), phosphine (Ready), phosphoramidite (Miyaura), sulfur-olefin (Xu)

D. This Work: Dynamic Kinetic Arylation of $\alpha$-Keto Esters<smiles>[R]C(C(=O)OCC)c1ccccc1</smiles><smiles>[Z]C1CCC(Br)C2CC1C=C2Br</smiles>

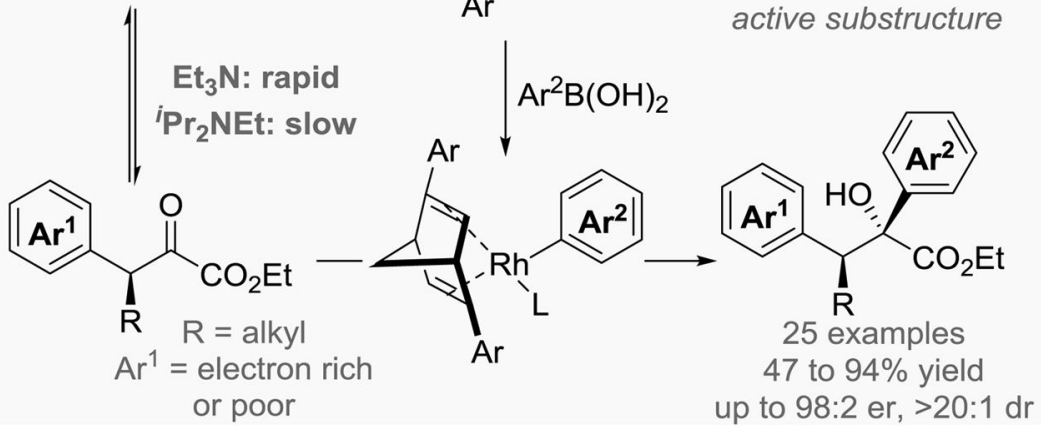

Scheme 1.

Background and Proposed Enantioconvergent Arylation 


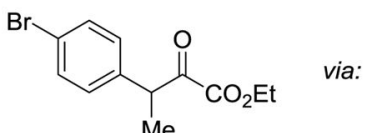

$( \pm)$

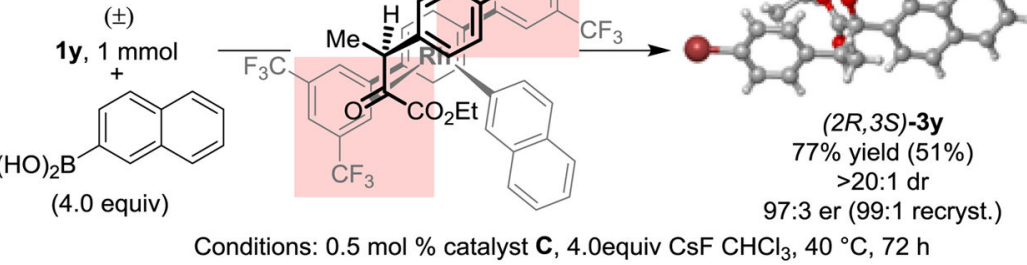

Scheme 2.

Mmol scale arylation and stereochemical model. 

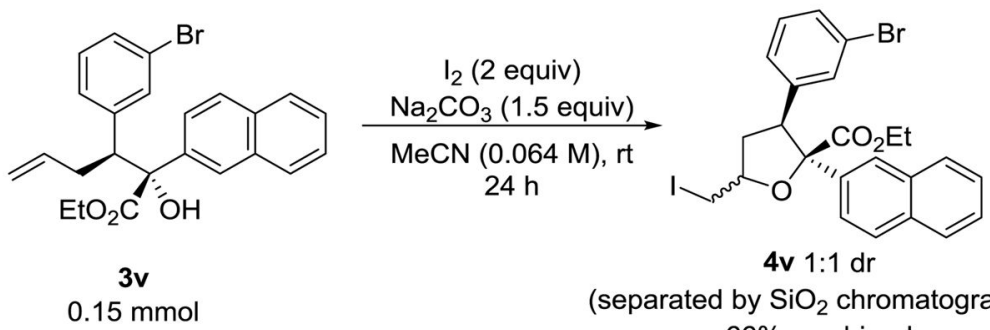

(separated by $\mathrm{SiO}_{2}$ chromatography) $66 \%$ combined

Scheme 3.

Iodoetherification of $3 \mathrm{v}$. 


\section{롤 \\ 굴}

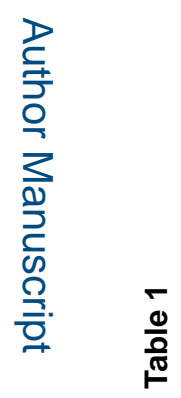

ᄅ⿳亠口冋.
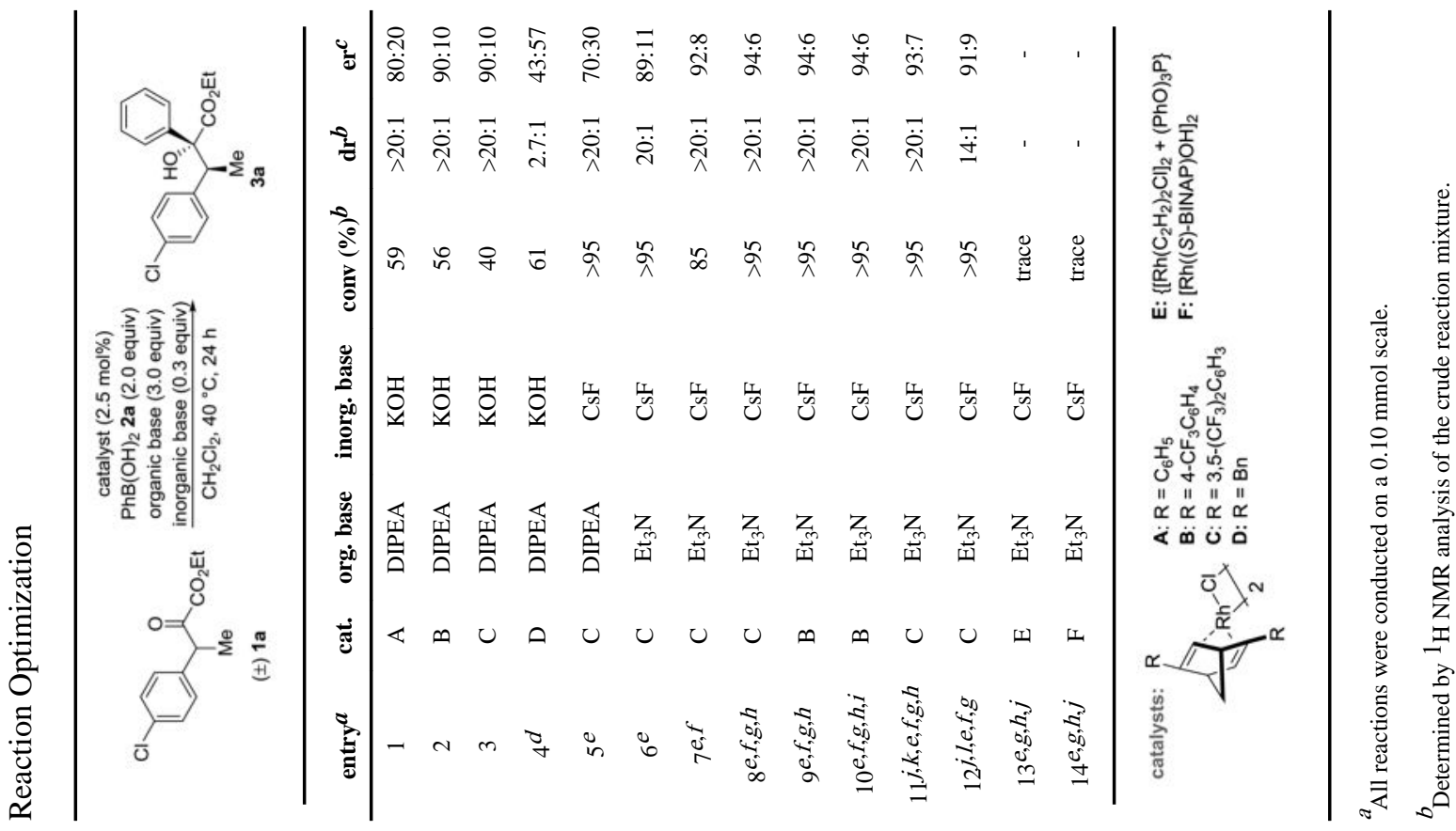

J Am Chem Soc. Author manuscript; available in PMC 2018 March 15. 

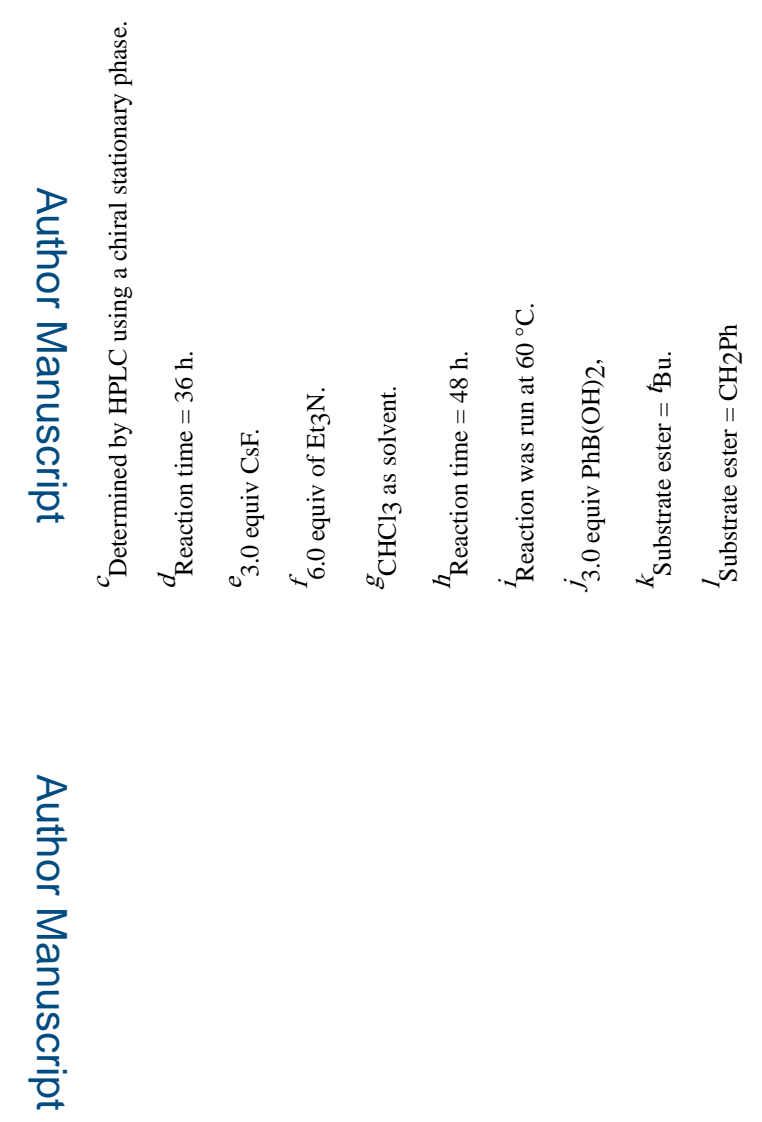

로을

롤

J Am Chem Soc. Author manuscript; available in PMC 2018 March 15. 
Table 2

Scope of Dynamic Kinetic Arylation Reaction.

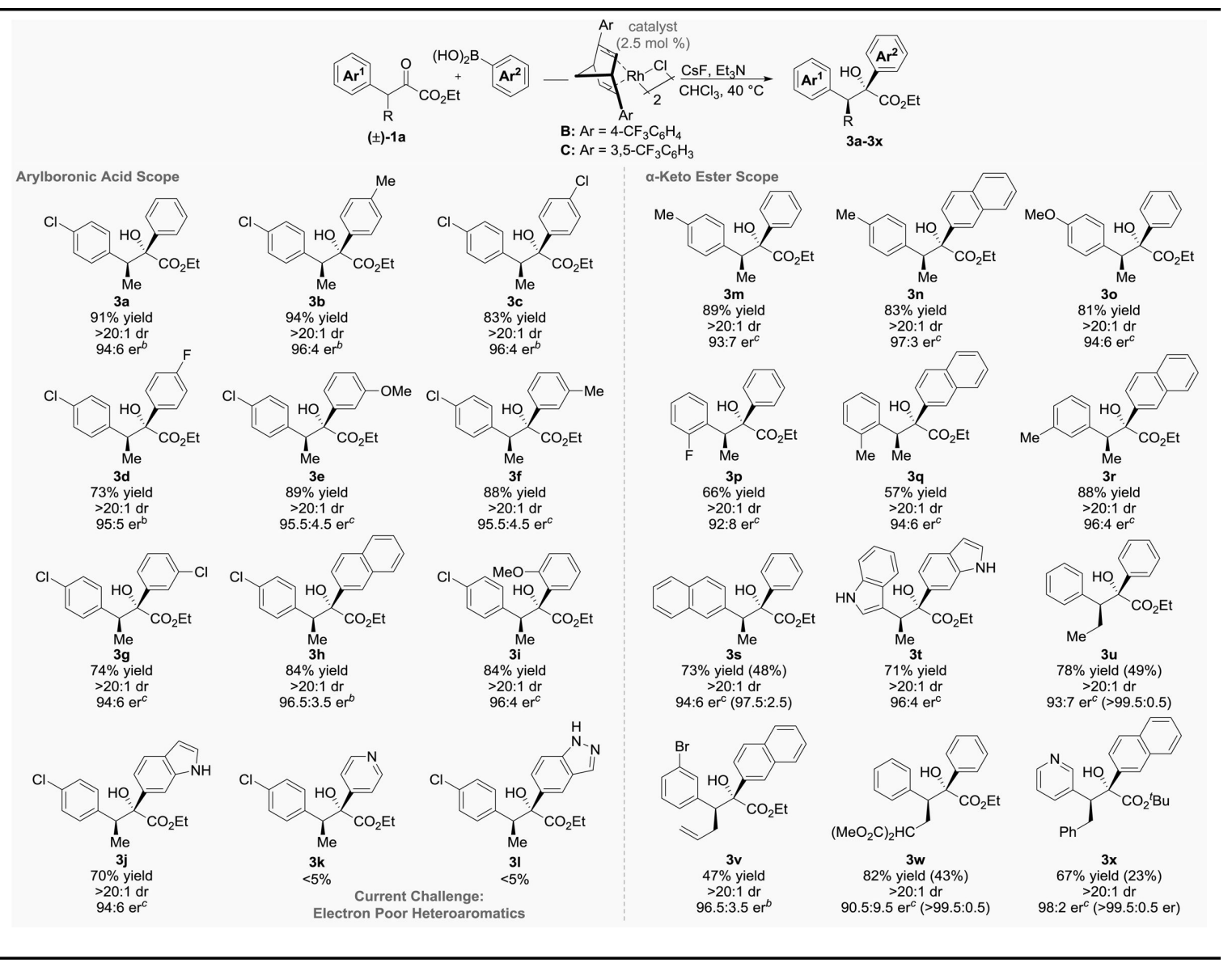

${ }^{a}$ Reactions run on $0.1 \mathrm{mmol}$ scale for $48 \mathrm{~h}$ or $60 \mathrm{~h}$ (see SI for individual reaction times and boronic acid equivalents), reported yields and er values are averages of two runs. Values in parentheses represent recrystallized yields and enantiomeric ratios.

${ }^{b}$ Catalyst B employed.

${ }^{c}$ Catalyst $\mathbf{C}$ employed. 